\title{
Penerapan Bagan Kendali Multivariat Robust Pada Data Produksi Pupuk ZK PT Petrokimia Gresik
}

\author{
Darmanto*1) $^{*}$, Heni Kusdarwati ${ }^{1)}$, Atiek Iriany $^{1)}$, Iwan Setiyawan ${ }^{2)}$ dan Ayu Aisyah Ashari ${ }^{1)}$ \\ 1) Jurusan Statisika, FMIPA, Universitas Brawijaya, Jln. Veteran 1 - Malang, 65145, Indonesia \\ ${ }^{2)}$ PT. Petrokimia Gresik, Jln. Jendral Ahmad Yani - Gresik, Indonesia
}

DOI: 10.20961/performa.17.1.18514

\begin{abstract}
Abstrak
PT Petrokimia Gresik merupakan produsen pupuk terlengkap se-Indonesia dan satu di antara sekian produksinya adalah pupuk ZK. Ada lima bahan kimia terukur yang berkorelasi membentuk pupuk $\mathrm{ZK}$ yaitu $\mathrm{H}_{2} \mathrm{O}, \mathrm{H}_{2} \mathrm{SO}_{4}, \mathrm{~K}_{2} \mathrm{O}, \mathrm{SO}_{3}$ dan $\mathrm{Cl}^{-}$. Proses monitoring pupuk ZK secara statistik belum pernah dilakukan oleh PT Petrokimia Gresik, baik secara univariat maupun multivariat. Dikarenakan pupuk ZK tersusun atas lima bahan kimia yang saling berkorelasi, maka digunakan bagan kendali multivariat. RMCD adalah salah satu metode pendugaan parameter yang robust terhadap data pencilan. Vektor rata-rata dan matriks varians-kovarians yang diperoleh dari metode RMCD digunakan untuk menghitung statistik pada bagan kendali multivariat. Oleh karena itu, bagan kendali robust lebih sensitif mendeteksi adanya pergeseran proses produksi dibandingkan dengan yang klasik. Data yang digunakan pada Fase I adalah data harian per 1 Januari - 30 April 2017, sedangkan Fase II data yang digunakan adalah data harian per 1 Mei - 15 Juli 2017. Hasil analisis bagan kendali pada Fase I menunjukkan bahwa proses produksi belum terkendali secara statistik sehingga dilakukan analisis diagram sebab-akibat. Lebih lanjut, batas bagan kendali pada Fase I yang telah stabil paska perbaikan, digunakan untuk data produksi Fase II. Hasil analisis bagan kendali pada Fase II menunjukkan bahwa proses produksi telah mengalami pergeseran. Hal ini dapat diketahui dengan banyaknya titik $T_{R M C D}^{2}$ yang keluar batas bagan kendali.
\end{abstract}

Kata kunci: Bagan Kendali Multivariat Robust, PT Petrokimia Gresik, RMCD

\begin{abstract}
PT Petrokimia Gresik is the most complete fertilizer producer in Indonesia and one of its production is ZK fertilizer. There are five measurable chemicals that correlate to form $\mathrm{ZK}$ fertilizer ie $\mathrm{H}_{2} \mathrm{O}, \mathrm{H}_{2} \mathrm{SO}_{4}, \mathrm{~K}_{2} \mathrm{O}, \mathrm{SO}_{3}$ and $\mathrm{Cl}$. $\mathrm{ZK}$ fertilizer monitoring process has not been statistically done by PT Petrokimia Gresik, either univariat or multivariate. Since ZK fertilizer is composed of five chemicals that correlate each other, a multivariate control chart is used. RMCD is one of the robust parameter estimation methods for outlier data. The average vector and variance-covariance matrix derived from the RMCD method is used to calculate the statistics on the multivariate control chart. Therefore, the robust control chart is more sensitive to detecting a shift in production processes compared to the classical ones. The data used in Phase I is daily data per January 1 - April 30, 2017, while Phase II data used is daily data as of May 1 - July 15, 2017. The results of the control chart analysis in Phase I shows that the production process has not been controlled statistically analysis of cause-effect diagrams. Furthermore, the control chart limits in Phase I that have been stable after the repair are used for Phase II production data. The result of the control chart analysis in Phase II shows that the production process has shifted. This can be known by the number of points $T_{\mathrm{RMCD}}^{2}$ that out of control.
\end{abstract}

Keywords: Robust Multivaraite Control Chart, PT Petrokimia Gresik, RMCD

\section{Pendahuluan}

Pupuk merupakan salah satu bagian penting dalam upaya meningkatkan hasil tanam di dunia pertanian. Penggunaan pupuk yang sesuai dengan prosedur atau anjuran diharapkan mampu memberikan dampak positif secara ekonomi bagi para petani. Selain terkait dengan prosedur penggunaan pupuk yang tepat, kualitas dari pupuk yang digunakan juga merupakan hal yang sangat penting dan perlu diperhatikan terutama bagi produsen pupuk. Hal ini dikarenakan jika pemanfaatan pupuk yang sangat tinggi di kalangan petani tidak diimbangi oleh kualitas pupuk yang baik, maka, menurut Bangun, dkk. (2000), akan dapat menimbulkan permasalahan defisiensi unsur mikro, pemadatan tanah dan pencemaran lingkungan.

Salah satu produsen pupuk terlengkap di Indonesia adalah PT. Petrokimia Gresik yang resmi beroperasi pada tanggal 10 Juli 1972. PT. Petrokimia Gresik setidaknya memproduksi tujuh jenis pupuk, baik pupuk anorganik maupun organik. Salah satu produk pupuk anorganik yang diproduksi oleh PT. Petrokimia Gresik adalah pupuk Zwavelzuur Kalium (ZK). Menurut Badan Standarisasi Nasional (BSN), Pupuk ZK adalah

*Korespondensi : darman_stat@ub.ac.id 
pupuk anorganik berbentuk butiran atau serbuk dengan rumus kimia $\mathrm{K}_{2} \mathrm{SO}_{4}$ yang dimanfaatkan sebagai sumber hara kalium dan belerang. Produk pupuk ZK yang dihasilkan oleh PT. Petrokimia Gresik berupaya mengikuti Standar Nasional Indonesia (SNI) nomor seri 02-2809-2005 dengan beberapa kriteria batas (minimum atau maksimum) kandungan kimiawi dari pupuk ZK sebagaimana pada tabel 1.

Tabel 1. Syarat Kualitas SNI 02-2809-2005 untuk Pupuk ZK

\begin{tabular}{clcc}
\hline No. & Uraian & Satuan & Persyaratan \\
\hline 1. & $\mathrm{H}_{2} \mathrm{O}$ & $\%$ & Maks. 1 \\
2. & $\mathrm{K}_{2} \mathrm{O}$ & $\%$ & Min. 50 \\
3. & $\mathrm{SO}_{3}$ & $\%$ & Min. 42,5 \\
4. & Free & $\%$ & Maks. 2,5 \\
& Acid & & \\
5. & $\mathrm{Cl}^{-}$ & $\%$ & Maks. 1,5 \\
\hline
\end{tabular}

(Sumber: http://www.bsn.go.id, tanggal akses 10/03/2018)

Pada periode sebelumnya, dalam memonitor proses produksi terutama produk yang dihasilkan apakah telah sesuai dengan SNI ataukah tidak, PT. Petrokimia Gresik hanya menggunakan statistika deskriptif sehingga prinsip pengendalian kualitas di PT ini kurang representatif. Oleh karena itu, perlu dilakukan analisis lebih mendalam terkait dengan kualitas dari produk yang dihasilkan oleh PT. Petrokimia Gresik. Salah satunya adalah dengan memonitor dan mengevaluasi produk dengan menggunakan bagan kendali. Bagan kendali sangat efektif untuk memonitor dan mengevaluasi apakah proses produksi tetap menghasilkan produk sesuai standar ataukah tidak. Berdasarkan karakteristik kualitas yang dimonitor dan dievaluasi, bagan kendali terbagi menjadi 2 yaitu bagan kendali univariat dan bagan kendali multivariat. Bagan kendali univariate digunakan jika hanya ada 1 karakteristik kualitas yang dimonitor dan dievaluasi, sedangkan jika terdapat lebih dari 1 karakteristik kualitas yang dimonitor dan dievaluasi, maka bagan kendali multivariat yang digunaka (Montgomery, 2009; Mason dan Young, 2002).

Dikarenakan pupuk ZK terdiri atas 5 kandungan kimiawi yang saling berkorelasi, maka bagan kendali yang digunakan adalah bagan kendali multivariat. Untuk tujuan peningkatan sensitifitas bagan kendali, penulis menerapkan bagan kendali multivariat robust berbasis re-weighted minimum covariance determinant (RMCD) pada data produksi pupuk ZK (Montgomery, 2009; Chenouri, dkk., 2009). Selain itu, penulis memaparkan analisis sebab-akibat jika dalam analisis bagan kendali terdapat observasi yang keluar batas kendali dengan menggunakan diagram tulang ikan (fishbone diagram).

\section{Metode Penelitian}

Data yang digunakan pada makalah ini adalah data harian produksi pupuk ZK oleh PT. Petrokimia Gresik yang dibagi menjadi dua Fase monitoring yaitu Fase I: Data produksi pupuk ZK pada tanggal 1 Januari - 30 April 2017 dan Fase II: Data produksi pupuk ZK pada tanggal 1 Mei - 15 Juli 2017.

Ada beberapa tahapan yang dilakukan dalam menerapkan bagan kendali multivariat berbasis RMCD yaitu pada Fase I dilakukan pendugaan terhadap vektor rata-rata dan matriks kovarians dengan algoritma RMCD yaitu menentukan subset $H_{1}$, dengan data sebanyak $h=\frac{m+p+1}{2}=\frac{120+5+1}{2}=63$ dari data awal berukuran $m$. Selanjutnya menghitung vektor rata-rata $\overline{\mathbf{x}}_{H_{1}}$ dan matriks kovarians $\mathbf{S}_{H_{1}}$ berdasarkan seluruh observasi pada subset $H_{1}$, kemudian dengan menggunakan rumus $R D_{i}^{2}=\left(\mathbf{X}_{i}-\overline{\mathbf{X}}_{R D}\right)^{\prime} \mathbf{S}_{R D}^{-1}\left(\mathbf{X}_{i}-\overline{\mathbf{X}}_{R D}\right)$, menghitung jarak untuk seluruh $i=1,2, \ldots, m$ di mana $d_{H_{1}}^{2}(i)=d_{R D}^{2}(i)$ dengan $\overline{\mathbf{x}}_{R D}=\overline{\mathbf{x}}_{H_{1}}$ dan $\mathbf{S}_{R D}=\mathbf{S}_{H_{1}}$. Langkah berikutnya adalah mengurutkan $d_{H_{1}}^{2}(i)$ secara ascending, $d_{H_{1}}^{2}\left(\pi_{1}\right) \leq d_{H_{1}}^{2}\left(\pi_{2}\right) \leq \ldots \leq d_{H_{1}}^{2}\left(\pi_{m}\right)$ di mana $\pi$ adalah kombinasi pada $\{1,2, \ldots, m\}$.

Setelah mengurutkan $d_{H_{1}}^{2}(i)$, berikutnya adalah mendefinisikan $H_{2}=\left\{X_{\left(_{\sigma_{1}},\right.}, X_{{\left(\sigma_{2}\right.}_{2},}, \ldots, X_{\left(\sigma_{2}\right)}\right\}$, kemudian menghitung vektor rata-rata $\overline{\mathbf{x}}_{\mathrm{H}_{2}}$, matriks kovarians $\mathbf{S}_{\mathrm{H}_{2}}$, dan $d_{H_{2}}^{2}(i)$. Jika $\operatorname{det}\left(\mathbf{S}_{H_{2}}\right)=0$, maka subset $H_{2}=H_{1}$. Kemudian mengulangi 5 tahapan sebelumnya untuk mendapatkan anggota subset $H$ yang berbeda (misal: 500 kali). Setelah mendapatkan subset $H$, selanjutnya adalah memilih 10 subset yang menghasilkan nilai determinan terkecil berdasarkan 500 subset $H$ yang telah dihitung determinannya dari 5 langkah sebelumnya dan kemudian melanjutkan proses iterasi untuk 10 subset terkecil terpilih hingga konvergen (iterasi ke-k) yakni diperoleh kondisi untuk masing-masing subset: $\operatorname{det}\left(\mathbf{S}_{H_{1}}\right) \geq \operatorname{det}\left(\mathbf{S}_{H_{2}}\right) \geq \ldots \geq \operatorname{det}\left(\mathbf{S}_{H_{k}}\right)=\operatorname{det}\left(\mathbf{S}_{H_{k+1}}\right)$. Selanjutnya adalah membandingkan determinan dari 10 subset yang telah konvergen, pilih satu determinan yang paling kecil di antara kesepuluh determinan tersebut. Setelah mendapatkan $\overline{\mathbf{x}}_{H_{k}}$ dan $\mathbf{S}_{H_{k}}$, maka diperoleh jarak berdasarkan rumusan: 


$$
d_{H_{k}}^{2}(i)=\left(\mathbf{X}_{i}-\overline{\mathbf{X}}_{H_{k}}\right)^{\prime} \mathbf{S}_{H_{k}}^{-1}\left(\mathbf{X}_{i}-\overline{\mathbf{X}}_{H_{k}}\right)
$$

Untuk mendapatkan konsistensi distribusi data yang dibangkitkan dari distribusi normal multivariat, maka didefinisikan: $\overline{\mathbf{x}}_{0}=\overline{\mathbf{x}}_{H_{k}}$ dan $\mathbf{S}_{0}=\frac{\operatorname{med}_{\left(d_{t_{k}}^{2}(i)\right)}}{\chi_{p, 0.5}^{2}} \mathbf{S}_{H_{k}}$

Tahap berikutnya adalah pemberian bobot pada statistik yang telah diperoleh pada tahap sebelumnya. Bobot 1 diberikan pada $d_{0}^{2}(i)$ yang secara statistik tidak termasuk dalam kategori pencilan, sedangkan 0 untuk jarak yang terdeteksi pencilan, yaitu $w_{i}=\left\{\begin{array}{lr}1, \text { jika } d_{0}^{2}(i) \leq \chi_{p, 0.975}^{2} \\ 0, & \text { selainnya }\end{array}\right.$

Berdasarkan rumus (3) maka didapatkan

$$
\begin{aligned}
\overline{\mathbf{x}}_{R M C D} & =\frac{\sum_{i=1}^{m} w_{i} \mathbf{x}_{i}}{\sum_{i=1}^{m} w_{i}} \\
\mathbf{S}_{R M C D} & =\frac{\sum_{i=1}^{m} w_{i}\left(\mathbf{x}_{i}-\overline{\mathbf{x}}_{R M C D}\right)\left(\mathbf{x}_{i}-\overline{\mathbf{x}}_{R M C D}\right)^{\prime}}{\sum_{i=1}^{m} w_{i}-1}
\end{aligned}
$$

Berdasarkan rumusan (4), maka diperoleh:

(Rousseeuw dan Driessen, 1999)

$$
T_{R M C D}^{2}(i)=\left(\mathbf{X}_{i}-\overline{\mathbf{X}}_{R M C D}\right)^{\prime} \mathbf{S}_{R M C D}^{-1}\left(\mathbf{X}_{i}-\overline{\mathbf{X}}_{R M C D}\right), i=1,2, \ldots, m .
$$

Rumusan (5) digunakan untuk menghitung statistik $T_{R M C D}^{2}(i)$ untuk tiap-tiap observasi per 1 Januari - 30 April 2017. Kemudian membuat bagan kendali multivariat robust berbasis RMCD dengan rumus batas kendali atas (BPA) berikut (Chenouri, dkk., 2009):

$$
\begin{aligned}
B P A & =f_{p, 1-\alpha, \gamma}(m)=\chi_{(p, 1-\alpha)}^{2}+\frac{a_{1, p, 1-\alpha, \gamma}}{m^{a_{2, p 1-\alpha, \gamma}}} \\
& =\chi_{(5,0.99)}^{2}+\frac{a_{1,5,0.99,0.5}}{120^{a_{2,0,0,0,0}}}=15,086+\frac{401744,3}{120^{2,618}}=16,534 .
\end{aligned}
$$

dan $B P B=0$.

Setelah mendapatkan nilai $B P A$ dan $B P B$ langkah berikutnya adalah memplotkan statistik $T_{R M C D}^{2}(i)$ ke bagan kendali yang telah terbentuk. Jika $T_{R M C D}^{2}(i)>B P A$, maka dilakukan analisis manajemen untuk mengetahui penyebab observasi keluar batas kendali kemudian mengeliminasi titik-titik yang keluar batas kendali. Setelah mengeliminasi titik-titik yang keluar batas, maka menghitung kembali batas kendali dengan $m$ sisa. Jika semua telah terkendali, maka batas digunakan untuk Fase II.

Pada Fase II, dengan menggunakan statistik $\overline{\mathbf{X}}_{R M C D}, \mathbf{S}_{R M C D}$ dan BPA pada Fase I untuk menghitung statistik $T_{\text {вмсл }}^{2}$ (i) dengan data yang digunakan pada Fase II dan memplotkannya pada bagan kendali yang ada. Selanjutnya adalah mengevaluasi titik-titik observasi yakni $T_{R M C D}^{2}(i)>B P A$, maka dinyatakan bahwa proses produksi tidak terkendali secara statistik atau dengan kata lain, vektor rata-rata telah bergeser dari yang sebenarnya. Jika terdapat titik-titik keluar batas kendali, maka dianalisis secara manajemen penyebab keluar batas dengan fishbone diagram.

\section{Hasil dan Pembahasan}

Statistik deskriptif merupakan bagian dari statistika yang mempelajari alat, teknik atau prosedur yang digunakan untuk menggambarkan atau mendeskripsikan kumpulan data atau hasil pengamatan. Data yang dikumpulkan tersebut perlu disajikan supaya mudah dimengerti, menarik, komunikatif dan informatif bagi pihak lain. Contoh statistika deskriptif yaitu penyajian data dalam bentuk tabel, diagram dan grafik. Sebelum dilakukan analisis grafik kendali $T_{R M C D}^{2}(i)$, terlebih dahulu dilakukan analisis deskriptif. Secara deskriptif, kelima karakteristik kualitas produk $\mathrm{ZK}$ yaitu $\mathrm{H}_{2} \mathrm{O}, \mathrm{K}_{2} \mathrm{O}, \mathrm{SO}_{3}, \mathrm{FA}$ sebagai $\mathrm{H}_{2} \mathrm{SO}_{4}$ dan $\mathrm{Cl}^{-}$disajikan pada Tabel 2. 
Tabel 2. Hasil Analisis Statistika Deskriptif Produk Pupuk ZK per 1 Januari - 30 April 2017

\begin{tabular}{ccccc}
\hline Kandungan & Rata-rata & Simpangan Baku & Minimum & Maksimum \\
\hline $\mathrm{H}_{2} \mathrm{O}$ & 0,134 & 0,065688 & 0,04 & 0,34 \\
$\mathrm{~K}_{2} \mathrm{O}$ & 51,6535 & 0,378896 & 50,73 & 52,77 \\
$\mathrm{SO}_{3}$ & 43,75483 & 0,654303 & 40,75 & 44,8 \\
$\mathrm{FA}$ & 1,45525 & 0,552008 & 0,1 & 3,08 \\
$\mathrm{Cl}$ & 1,155417 & 0,525677 & 0,31 & 3,77 \\
\hline
\end{tabular}

Berdasarkan statistika deskriptif pada Tabel 2, diperoleh informasi bahwa karakteristik $\mathrm{H}_{2} \mathrm{O}$ sebagian besar berat yang dihasilkan sebesar $0,134 \%$, dengan berat minimum sebesar $0,04 \%$ dan berat maksimum sebesar $0,34 \%$ serta besarnya penyimpangan data sebesar 0,0666. Karakteristik $\mathrm{K}_{2} \mathrm{O}$ sebagian besar berat yang dihasilkan sebesar 51,654\%, dengan berat minimum sebesar 50,73\% dan berat maksimum sebesar $52,77 \%$ serta besarnya penyimpangan data sebesar 0,379 . Karakteristik $\mathrm{SO}_{3}$ sebagian besar berat yang dihasilkan sebesar $43,755 \%$, dengan berat minimum sebesar $40,75 \%$ dan berat maksimum sebesar $44,8 \%$ serta besarnya penyimpangan data sebesar 0,654 .

Adapun Karakteristik FA sebagai $\mathrm{H}_{2} \mathrm{SO}_{4}$ sebagian besar berat yang dihasilkan sebesar $1,455 \%$, dengan berat minimum sebesar $0,1 \%$ dan berat maksimum sebesar 3,08\% serta besarnya penyimpangan data sebesar 0,5520 . Sedangkan karakteriktik $\mathrm{Cl}^{-}$sebagian besar berat yang dihasilkan sebesar $1,155 \%$, dengan berat minimum sebesar $0,31 \%$ dan berat maksimum sebesar 3,77\%, serta besarnya penyimpangan data sebesar 0,5256. Berdasarkan Tabel 2 juga dapat dapat dilihat bahwa terdapat karakteristik yang tidak sesuai dengan spesifikasi yang telah ditetukan perusahaan, yaitu nilai minimum dari $\mathrm{SO}_{3}$ yang seharusnya $42,5 \%$ menjadi 40,75\%, nilai maksimum FA sebagai $\mathrm{H}_{2} \mathrm{SO}_{4}$ yang seharusnya $2,5 \%$ menjadi $3,08 \%$ dan nilai maksimum $\mathrm{Cl}^{-}$ yang seharusnya $1,5 \%$ menjadi $3,77 \%$.

Tahapan selanjutnya adalah menganalisis observasi dengan menggunakan bagan kendali multivariat robust RMCD. Proses pendugaan statistik vektor rata-rata dan matriks kovarian RMCD dilakukan dengan menggunakan bantuan paket program R. Demikian juga untuk pembuatan bagan kendali juga menggunakan paket program $\mathrm{R}$. Berdasarkan perhitungan, diperoleh statistik vektor rata-rata dan matriks kovarians berbasis RMCD sebagai berikut:

$$
\overline{\mathbf{x}}_{\text {RMCD }}=\left[\begin{array}{r}
0,108 \\
51,669 \\
43,789 \\
1,520 \\
1,125
\end{array}\right] ; \mathbf{S}_{R M C D}=\left[\begin{array}{rrrrr}
0,00146 & -0,00226 & 0,00339 & 0,00285 & -0,00220 \\
-0,00226 & 0,11619 & -0,11351 & -0,11640 & 0,07096 \\
0,00339 & -0,11351 & 0,29250 & 0,19707 & -0,22388 \\
0,00285 & -0,11640 & 0,19707 & 0,26994 & -0,09677 \\
-0,00220 & 0,07096 & -0,22388 & -0,09677 & 0,19303
\end{array}\right]
$$

Sehingga dapat diperoleh plot Fase I pertama adalah sebagaimana pada Gambar 2 dengan batas kendali yang telah dihitung pada sub-bab metode.

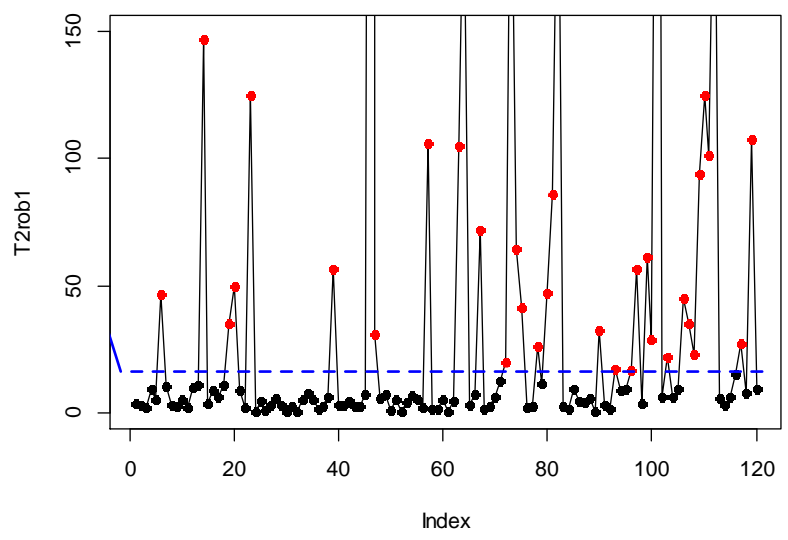

Gambar 2. Plot Bagan Kendali Multivariat Robust Fase I Pertama

Berdasarkan Gambar 2, dapat diketahui bahwa banyak titik-titik observasi yang keluar batas kendali sehingga perlu dievaluasi secara manajemen mengapa terdapat titik-titik yang keluar batas kendali. Ada beberapa hal secara manajemen yang menyebabkan titik-titik tersebut keluar batas kendali, dengan analisis grafik kendali univariat diperoleh beberapa informasi di antaranya adalah 
1. Pada karakteristik kualitas $\mathrm{SO}_{3}$ terdapat tiga observasi yang keluar batas kendali yaitu pada data ke-91, 92 dan 99 disebabkan oleh mesin yang mulai mengalami fatigue sehingga proses produksi tidak seimbang.

2. Observasi ke-13 dan 38 pada karakteristik kualitas FA keluar batas kendali. Hal ini disebabkan oleh start-up mesin setelah break beroperasi.

3. Pada karakteristik kualitas $\mathrm{Cl}^{-}$, banyak sekali titik-titik yang keluar batas kendali yaitu pada data ke-17, $46,51,52,53,68,69,70,75,80,86,88,90,91,92,93,99,102,111,112,114,116,117,118,119$ dan 120. Banyaknya titik yang keluar batas kendali pada karakteristik kualitas ini memungkinkan disebabkan oleh kalibrasi mesin yang tidak tepat atau faktor lain yang PT Petrokimia Gresik masih mencari solusinya.

Dikarenakan pada bagan kendali multivariat, semua karakteristik kualitas berkorelasi, maka satu titik yang keluar batas kendali dari salah satu karakteristik kualitas yang diamati secara simultan akan menyebabkan titik pada bagan kendali multivariat juga keluar batas kendali. Selanjutnya adalah mengeliminasi titik-titik tersebut dari analisis dan melakukan plot ulang pada data sisa yang berada dalam batas kendali sebagaimana pada Gambar 3. Berdasarkan Gambar 3, semua titik telah terkendali secara statistik dengan batas kendali sebagai berikut:

$$
\begin{aligned}
B P A & =f_{p, 1-\alpha, \gamma}(m)=\chi_{(p, 1-\alpha)}^{2}+\frac{a_{1, p, 1-\alpha, \gamma}}{m^{a_{2, p, 1-\alpha, \gamma}}} \\
& =\chi_{(5,0.99)}^{2}+\frac{a_{1,5,0,09,0.5}}{83^{a_{2,50.0,0 .}}}=15,086+\frac{401744,3}{83^{2,618}}=18,886 .
\end{aligned}
$$

dan $B P B=0$.

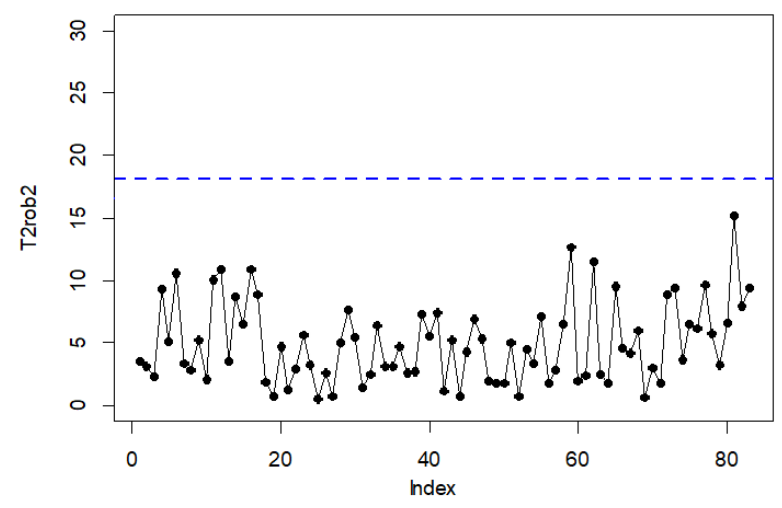

Gambar 3. Plot Bagan Kendali Multivariat Robust Fase I Kedua

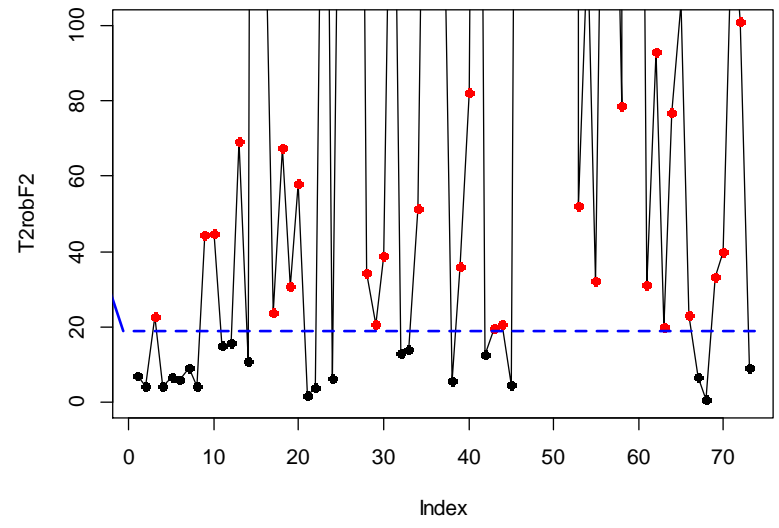

Gambar 4. Plot Bagan Kendali Multivariat Robust Fase II

Setelah Fase I terkendali secara statistik yang ditunjukkan dengan tidak adanya titik-titik observasi yang keluar batas kendali, maka tahapan selanjutnya adalah Fase II yang menganalisis proses produksi selanjutnya berdasarkan statistik vektor rata-rata, matriks kovarians dan batas kendali yang telah diperoleh pada Fase I Kedua (Grafik kendali terkendali). Adapun prosedur perhitungan statistik $T_{R M C D}^{2}(i)$ hingga memplotkan ke bagan kendali sebagaimana yang telah dijelaskan pada sub-bab metode analisis. Data yang digunakan pada Fase II adalah data produksi pupuk ZK per 1 Mei - 15 Juli 2017. Gambar 4 menunjukkan hasil analisis bagan kendali Fase II. Berdasarkan Gambar 4 dapat diketahui bahwa proses produksi masih belum stabil. Kondisi ini ditunjukkan dengan masih sangat banyaknya titik observasi yang keluar batas kendali.

Berdasarkan analisis bagan kendali sebagaimana pada Gambar 4 yang mengindikasikan bahwa proses produksi ZK PT. Petrokimia Gresik berjalan di luar standar SNI 02-2809-2005, maka perlu dibuat diagram sebab-akibat (fishbone diagram/diagram tulang ikan) sebagaimana pada Gambar 5 untuk mem-breakdown 
akar permasalahan kondisi keluar batas kendali (out of control). Diagram tulang ikan digunakan untuk menganalisis kualitas dengan tujuan untuk mengetahui secara menyeluruh hubungan antara kecacatan dengan penyebabnya. Berkaitan dengan pengendalian proses statistika, diagram sebab-akibat dipergunakan untuk menunjukan faktor-faktor penyebab (sebab) dan karateristik kualitas (akibat) yang disebabkan oleh faktor-faktor penyebab itu (Tague, 2005; Heizer dan Render, 2008). Berikut adalah hasil analisis secara ekspoloratori terhadap penyebab ketidakterkendalian produk ZK yang diproduksi oleh PT. Petrokimia Gresi yang menjelaskan tiap faktor pada diagram sebab-akibat pada Gambar 5:

\section{Material}

Dalam pembuatan produk pupuk ZK tidak terlepas dari adanya bahan baku yang akan digunakan, di PT Petrokimia Gresik mempunyai standar spesifikasi agar bahan baku yang akan digunakan memiliki kualitas yang baik, namun kualitas bahan baku tidak selalu baik sehingga akan menyebabkan karateristik kualitas dalam pupuk ZK tidak sesuai spesifikasi. Beberapa penyebab adanya kualitas bahan baku yang kurang baik diantaranya yaitu perusahaan ingin meminimalisir biaya yang bertujuan untuk menurunkan HPP (Harga Pokok Produksi), bahan baku rusak dalam penyimpanan karena tercampur dengan bahan baku lain yang diakibatkan oleh tempat penyimpanan yang sama serta bahan baku rusak terkena hujan karena disimpan di tempat yang terbuka. Penyimpanan di gudang yang berbeda untuk setiap bahan baku akan menjadi lebih efektif untuk mencegah bahan baku tercampur dengan bahan baku lain. Selain itu, untuk menghindari bahan baku itu rusak akibat terkena hujan maka sebaiknya disimpan di tempat yang tertutup.

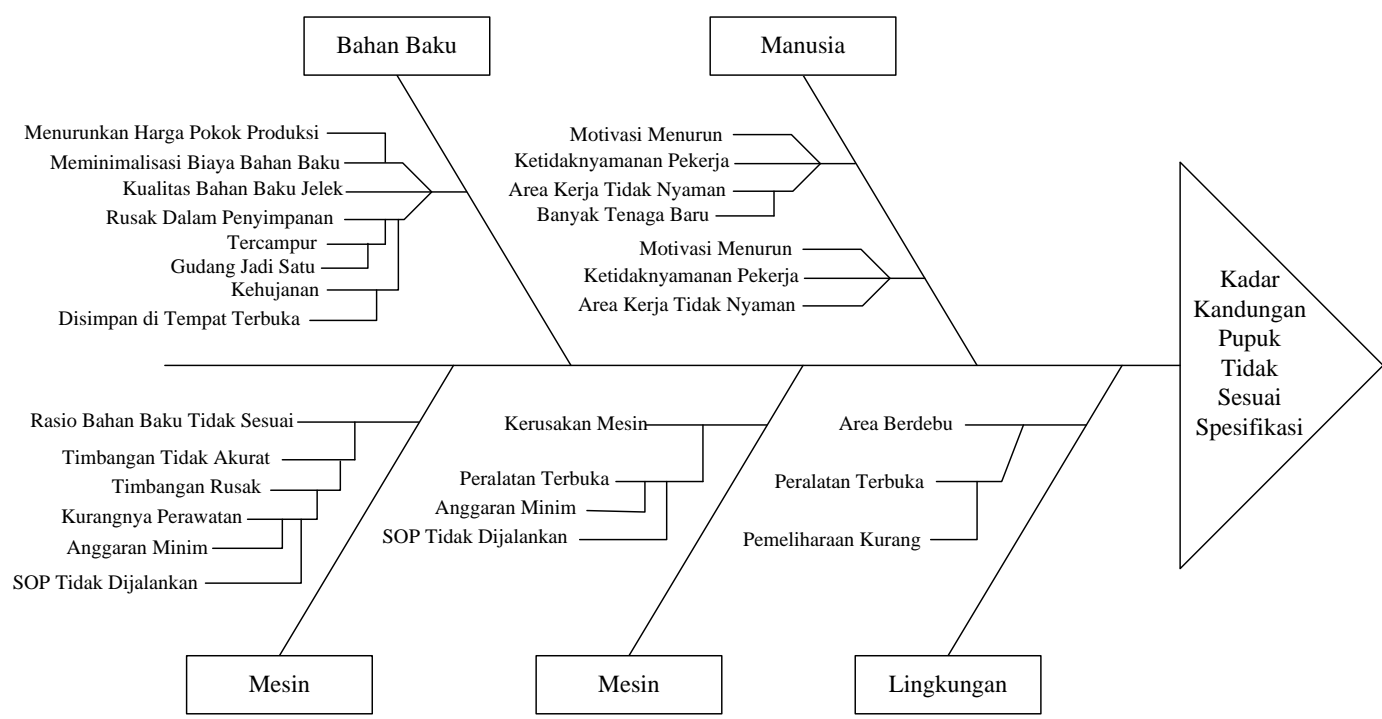

Gambar 5. Diagram Tulang Ikan Permasalahan Tidak Terkendalinya Proses Produksi Pupuk ZK PT. Petrokimia Gresik

\section{Metode}

Salah satu penyebab kadar kandungan kimia dalam pupuk ZK tidak sesuai spesifikasi yaitu faktor metode yang digunakan. Pada metode yang digunakan sering kali menemui rasio bahan baku yang tidak sesuai yang disebabkan karena timbangan yang rusak sehingga dalam penimbangan sering kali tidak akurat. Kurangnya perawatan menjadi salah satu penyebab timbangan yang rusak. Adapun beberapa penyebab kurangnya perawatan yaitu anggaran minimum dan SOP (Standard Operating Procedure) yang tidak dijalankan. Untuk meminimalisir masalah anggaran dana yang minimum yaitu dengan membuat list bagian perawatan pada timbangan agar dana yang dianggarkan lebih efektif. Sedangkan untuk SOP yang tidak dijalankan, perlunya melakukan sosialisasi dan pelatihan-pelatiahan mengenai SOP agar proses perawatan menjadi lebih optimal.

\section{Manusia}

Salah satu faktor yang mempengaruhi karakteristik kualitas dari pupuk ZK tidak sesuai spesifikasi yaitu faktor manusia. Pada faktor manusia dapat dilihat bahwa kompetensi yang kurang dari pekerja yang ada karena dari pengalaman kerja yang minim yang disebabkan banyaknya tenaga baru dan kurangnya pelatihan pada pekerja. Kemudian dapat dilihat juga dari ketidaknyamanan pekerja yang disebabkan area kerja yang tidak nyaman dan motivasi pekerja yang turun. Untuk memperbaiki hal tersebut dapat diatasi dengan menambah pelatihan pada pekerja dan arahan pada tenaga kerja baru agar lebih kompeten, memberikan motivasi pada pekerja dengan mengadakan diklat ruang dan memberikan fasilitas serta kenyamanan pada area kerja para pekerja.

4. Mesin

Produk yang berkualitas dapat dilihat dari karakteristik kualitas yang tidak lebih atau tidak kurang dari standar yang ditetapkan perusahaan. Mesin mempunyai pengaruh yang besar terhadap kualitas produksi. 
Adanya kerusakan pada mesin menyebabkan pabrik tidak dapat beroperasi, sehingga perusahaan akan kehilangan banyak omset dan akan mengurangi kualitas dari produk yang dihasilkan. Ketika mesin mati dan mulai beroperasi kembali keadaan mesin juga menjadi tidak stabil. Kerusakan pada mesin disebabkan karena kurangnya perawatan akibat dari dana yang dianggarkan untuk pemeliharaan mesin kurang dan SOP (Standard Operating Procedure) yang tidak dijalankan dengan baik. Kedua hal tersebut menjadi penyebab adanya ketidaksesuaian karakteristik kualitas pada produksi pupuk Urea. Untuk meningkatkan proses produksi karena adanya karakteristik yang tidak sesuai spesifikasi yaitu dengan membuat list bagian alat yang penting di setiap equipment sehingga anggaran dana yang terserap menjadi efektif, melakukan sosialisasi mengenai SOP (Standard Operating Procedure) dan efek terhadap alat apabila SOP (Standard Operating Procedure) tidak dijalankan dengan baik, serta dilakukan pengkajian ulang SOP (Standard Operating Procedure) agar proses perawatan di suatu equipment menjadi lebih optimal.

\section{Lingkungan}

Lingkungan merupakan salah satu faktor pendukung yang sangat penting dalam penentuan kualitas produk pupuk ZK. Area berdebu merupakan salah satu faktor lingkungan yang menyebabkan kadar kandungan pupuk ZK tidak sesuai spesifikasi. Adanya peralatan pabrik yang terbuka menjadi penyebab utama area yang berdebu. Hal itu terjadi karena kurangnya pemeliharaan terhadap peralatan tersebut. Pada hal tersebut dapat dilakukan pemeliharaan yaitu dengan memastikan prosedur perawatan sesuai dengan SOP yang berlaku atau tidak serta membuat skala prioritas terhadap peralatan atau mesin yang membutuhkan perawatan ekstra menjadi solusi yang dapat meningkatkan proses produksi sehingga meminimalisir produk yang tidak sesuai spesifikasi. Diagram tulang ikan bersifat teoritis dan belum dilakukan verifikasi karena keterbatasan waktu. Namun, diagram tulang ikan yang telah disusun dapat digunakan sebagai acuan analisis kualitas pupuk ZK.

\section{Simpulan}

Berdasarkan hasil analisis yang telah dilakukan, dengan menggunakan bagan kendali robust multivariat RMCD pada Fase I tahap 1 diketahui bahwa banyak titik amatan yang tidak terkendali secara statistik yang diindikasikan dengan keluarnya plot dari $B P A$. Namun, setelah titik-titik tidak terkendali dieliminasi dan dikalkulasi ulang $B P A$ (Fase I tahap 2), diperoleh keadaan terkendali sehingga $B P A$ baru tersebut digunakan untuk proses monitor dan evaluasi pada Fase II. Namun demikian, dengan data Fase II yaitu data produksi ZK yaitu periode $1 \mathrm{Mei}$ - 15 Juli 2017 sebagaimana yang diulas pada hasil analisis, dengan menggunakan $B P A$ baru yang diperoleh pada Fase I tahap 2, terdapat banyak titik amatan yang berada di luar $B P A$, sehingga dapat disimpulkan bahwa hingga per Juli 2017, produksi pupuk ZK yang diproduksi oleh PT. Petrokimia Gresik secara statistik masih belum terkendali.

Selain itu, berdasarkan hasil analisis dengan diagram sebab-akibat diperoleh lima faktor penyebab produk ZK yang diproduksi oleh PT. Petrokimia Gresik adalah material, metode, manusia, mesin dan lingkungan. Pada konteks material dimungkinan disebabkan oleh bahan baku baik dari segi kualitas maupun harga. Adapun dari konteks metode, penyebab yang menjadikan produk ZK tidak terkendali dimungkinkan disebabkan oleh tidak dijalankannya SOP, sedangkan pada konteks manusia, sebab utama adalah kurang kompetensi akibat tidak ada pelatihan yang intens terhadap karyawan. Pada konteks mesin dimungkinkan disebabkan oleh keausan mesin atau matinya mesin ketika sedang beroperasi. Faktor penyebab terakhir adalah lingkungan yang disebabkan oleh kondisi lingkungan kerja.

Sebagai saran, pada penelitian selanjutnya dapat dilakukan dekomposisi untuk penyebab ketidakterkendalian titik-titik amatan produk ZK. Dekomposisi dapat diterapkan pada kelima karakteristik kualitas yang mengkonstruksi produk $\mathrm{ZK}$ yaitu $\mathrm{H}_{2} \mathrm{O}, \mathrm{K}_{2} \mathrm{O}, \mathrm{SO}_{3}$, FA sebagai $\mathrm{H}_{2} \mathrm{SO}_{4}$ dan $\mathrm{Cl}^{-}$. Jadi, diharapkan pada penelitian selanjutnya dapat diperoleh informasi secara spesifik karakteristik kualias manakah yang menjadi penyebab tertinggi yang menjadikan ketidakterkendalian produk ZK yang diproduksi oleh PT. Petrokimia Gresik.

\section{Ucapan Terimakasih}

Penulis mengucapkan terimakasih kepada Fakultas MIPA, Universitas Brawijaya yang telah membiayai penelitian ini. Selain itu, penulis juga mengucapkan terimakasih kepada pihak PT. Petrokimia Gresik selaku mitra, dan juga kepada mahasiswa atas nama Ayu Aisyah Ashari yang telah membantu terselesainya penelitian ini.

\section{Daftar Pustaka}

Bangun, E., dkk.,. 2000. Pengkajian Teknologi Pemupukan Bawang Merah di Sumatera Utara. Prosiding Seminar Nasional Teknologi Spesifik Lokasi Menuju Desentralisasi Pembangunan Pertanian. 13-14 Maret 2000. Medan. Available from: http://pustaka.litbang.deptan.go.id/agritek/sltg0404.pdf. 
Chenouri, S., dkk., 2009. A Multivariate Robust Control Chart for Individual Observation. Journal of Quality Technology, Vol. 43, hal. 259-271.

Gunadi, N. 2009. Kalium Sulfat dan Kalium Klorida Sebagai Sumber Pupuk Kalium pada Tanaman Bawang Merah. J. Hortikultural. 19(2):174-185.

http://www.bsn.go.id, tanggal akses 10/03/2018.

Heizer, J. dan B. Render. 2008. Operation Management. Edisi 9. New Jersey: Prentice Hall, Inc.

Mason, R.L. dan J.C. Young. 2002. Multivariate Statistical Process Control with Industrial Applications. Volume 9 dari ASA-SIAM Series on Statistics and Applied Probability.

Montgomery, D. C. 2009. Introduction to Statistical Quality Control. Edisi ke-5. John Wiley \& Sons: New York.

Rousseeuw, P. J., \& Van Driessen, K. 1999. Fast Algorithm for Minimum Covariance Determinant Penduga. Technometrics, 41, hal. 212-223.

Tague, N. R. 2005. The Quality Toolbox. Edisi ke-2. Milwaukee Wisconsin: ASQ Quality Press. 